University of Nebraska - Lincoln

DigitalCommons@University of Nebraska - Lincoln

May 2000

\title{
Comparison of plasma FSH concentration in boars and gilts from lines selected for ovulation rate and embryonal survival, and litter size and estimation of (co)variance components for FSH and ovulation rate
}

R. K. Johnson

University of Nebraska-Lincoln, rjohnson5@unl.edu

J. J. Ford

USDA, ARS, Roman L. Hruska U.S. Meat Animal Research Center, Clay Center, NE

Follow this and additional works at: https://digitalcommons.unl.edu/animalscifacpub

Part of the Animal Sciences Commons

Johnson, R. K. and Ford, J. J., "Comparison of plasma FSH concentration in boars and gilts from lines selected for ovulation rate and embryonal survival, and litter size and estimation of (co)variance components for FSH and ovulation rate" (2000). Faculty Papers and Publications in Animal Science. 97. https://digitalcommons.unl.edu/animalscifacpub/97

This Article is brought to you for free and open access by the Animal Science Department at DigitalCommons@University of Nebraska - Lincoln. It has been accepted for inclusion in Faculty Papers and Publications in Animal Science by an authorized administrator of DigitalCommons@University of Nebraska - Lincoln. 


\title{
Comparison of plasma FSH concentration in boars and gilts from lines selected for ovulation rate and embryonal survival, and litter size and estimation of (co)variance components for FSH and ovulation rate r,2 $^{1,2}$
}

\author{
J. P. Cassady*, R. K. Johnson*,3, and J. J. Ford $\dagger$ \\ *Department of Animal Science, University of Nebraska, Lincoln 68533-0908 \\ and †USDA, ARS, Roman L. Hruska U.S. Meat Animal Research Center, Clay Center, NE 68933-0166
}

\begin{abstract}
The objective of this research was to determine whether plasma concentration of FSH was genetically correlated with ovulation rate and thus was a useful trait for indirect selection. Blood samples were collected from 619 animals from five lines of pigs. Line I was selected for increased index of ovulation rate and embryonal survival, and Line $\mathrm{C}$ was its randomly selected control. Pigs sampled from Lines I and C were from generations 12 and 13. Pigs from three additional lines that were derived from eighth-generation pigs of Lines I and C also were used. These lines were Line C2, a randomly selected control derived from Line C, Line COL, derived from Line $\mathrm{C}$, and Line IOL, derived from Line I; each of these lines was selected an additional five generations for increased ovulation rate and increased litter size. A single blood sample was collected from each pig between 46 to 63 (d 58), 86 to 98 (d 90), 110 to 133 (d 124), and 147 to 153 (d 150) d of age. The heritability of ovulation rate was .28 and heritabilities
\end{abstract}

of plasma concentration of FSH at d 58, 90, 124, and 150 were $.41, .25, .12$, and 0 , respectively. Genetic correlations between ovulation rate and d-58, d-90, and d124 plasma concentration of FSH were $.31, .23$, and 0 , respectively. Line I gilts had greater estimated breeding values for plasma concentration of FSH at $d 58$ and 90 than Line $\mathrm{C}$ gilts $(P<.01)$. Line $\mathrm{COL}$ gilts had greater estimated breeding values for plasma concentration of FSH at $\mathrm{d} 58$ than Line $\mathrm{C} 2$ gilts $(P<.01)$. Line I boars had greater estimated breeding values for plasma concentration of FSH at d 90 than Line $\mathrm{C}$ boars $(P<.05)$. Even though genetic correlations were low, selection for increased plasma concentration of FSH was estimated to be $93 \%$ as effective in changing ovulation rate as direct selection because selection for FSH can be practiced in both sexes. Thus, selection for increased plasma concentration of FSH seems to be a practical method for increasing ovulation rate in pig breeding programs without using laparoscopy.

Key Words: FSH, Ovulation Rate, Pigs, Selection

(O)2000 American Society of Animal Science. All rights reserved.

J. Anim. Sci. 2000. 78:1430-1435

\section{Introduction}

A greater rate of response in litter size at birth is expected from selection for ovulation rate and embryonal survival (Johnson et al., 1984) or ovulation rate and uterine capacity (Bennett and Leymaster, 1989) than from direct selection for litter size. Methods proposed by these authors include laparotomy or laparos-

\footnotetext{
${ }^{1}$ Published as paper no. 12674, Journal Ser., Nebraska Agric. Res. Div., Univ. of Nebraska, Lincoln 68583-0908.

${ }^{2}$ We thank Dr. Dias, New York State Department of Health, for FSH antisera and USDA/NIH distribution program for ovine FSH for iodination and reference preparation of porcine FSH.

${ }^{3}$ Current address: Dept. of Anim. Sci., Univ. of Nebraska, Lincoln 68533-0908. Correspondence: phone: 402-472-6407; fax: 402-4726362; E-mail: rjohnson5@unl.edu.

Received July 6, 1999.

Accepted January 11, 2000.
}

copy to measure ovulation rate and unilateral ovariectomy-hysterectomy to measure uterine capacity. These procedures are not practical in most industry breeding programs. Identification of a trait easily measured in young animals and genetically correlated with ovulation rate would make application of these models more practical. Even greater rates of response may occur if the correlated trait is measured in both sexes (Smith et al., 1983).

Gilts and sows of the Chinese Meishan breed have a greater ovulation rate than females of domestic breeds (Anderson et al., 1993; Christenson, 1993; White et al., 1993). Meishan boars also have greater plasma concentrations of FSH than Duroc and whiteline composite boars (Borg et al., 1993; Howard et al., 1993). The objectives of this research were, first, to estimate the heritability of plasma FSH concentration and genetic correlations between plasma concentration of FSH and ovulation rate. Second, we sought to determine the 
usefulness of plasma FSH as a selection criterion for increased ovulation rate. Finally, correlated responses in plasma concentration of FSH in pigs from populations selected for ovulation rate and embryonic survival or ovulation rate and litter size were estimated.

\section{Materials and Methods}

\section{Selection Methods and Population Management}

Pigs were from five lines. The base population for all lines was a composite of Large White and Landrace (Neal et al., 1989). Line I was selected 11 generations for increased index values of ovulation rate and embryonal survival, and Line $\mathrm{C}$ was its randomly selected control (Johnson et al., 1999). Lines C and I were contemporaries that farrowed in July and August. At generation 10, Line I differed from Line C by 6.7 ova, 3.3 fetuses, and $-4.5 \%$ embryonal survival to $50 \mathrm{~d}$ of gestation. At generation 12, Line I differed from Line C by 4.0 fully formed and 2.5 live pigs at birth (Johnson et al., 1999). There were approximately 45 litters by 15 sires in both Lines $\mathrm{I}$ and $\mathrm{C}$ in each of the first 11 generations.

After producing litters for the index selection experiment, generation 8 Line I and $\mathrm{C}$ dams and sires were mated again for second-parity litters. Their progeny were assigned to the three new lines farrowing in February and March. Two of these lines underwent twostage selection for increased ovulation rate, followed by selection for increased litter size. The third was a randomly selected control line. The control line was established by randomly selecting one gilt from each Line $\mathrm{C}$ litter and one son of each Line $\mathrm{C}$ sire. This line was designated as Line $\mathrm{C} 2$ and was selected in the same manner in all subsequent generations with 40 to 45 litters by 15 sires per generation. Remaining gilts from the largest $50 \%$ of the Line $\mathrm{C}$ litters based on number of fully formed pigs and one randomly selected boar from each of the 15 largest litters were designated as Line COL. Gilts were observed for estrus, and approximately $10 \mathrm{~d}$ after expression of their second estrus (first postpubertal estrus) laparotomy was used to count corpora lutea as a measure of ovulation rate. Gilts were ranked on ovulation rate, and the top $50 \%$ were selected and mated to selected boars to produce the next generation of progeny. Subsequent selection in Line COL continued in this same manner each generation. Thus, Stage 1 evaluation involved ranking litters on number of fully formed pigs. All gilts from those litters that were in the upper 50th percentile and one boar from each of the 15 largest litters were selected. In Stage 2 evaluation, laparotomy was performed to measure ovulation rate on each gilt retained during Stage 1. Gilts with ovulation rates in the upper 50th percentile were selected for mating. Selected gilts and boars were mated to produce the next generation of progeny, initiating another cycle of selection. There were 40 to 45 litters by 15 sires per generation.

Line IOL was formed from second-parity litters of Line I in generation 8 in the same manner as Line COL
Table 1. Diets

\begin{tabular}{lcccc}
\hline \hline Diet & Feeding period $^{\mathrm{b}}$ & \% CP & \% Lysine & ME, Mcal/kg \\
\hline Nursery & & & & \\
$1^{\mathrm{a}}$ & $1 \mathrm{wk}$ & 22.7 & 1.40 & 3.39 \\
$2^{\mathrm{a}}$ & $4 \mathrm{wk}$ & 18.9 & 1.00 & 3.44 \\
Growing $^{\mathrm{a}}$ & $6 \mathrm{wk}$ & 16.2 & .81 & 3.19 \\
Finishing $^{\mathrm{a}}$ & $8 \mathrm{wk}$ & 14.0 & .65 & 3.20 \\
\hline
\end{tabular}

${ }^{\mathrm{a}} \mathrm{Fed}$ for ad libitum consumption.

${ }^{\mathrm{b}}$ Length of time diets were fed.

was formed from Line C. Subsequent selection in Line IOL was as described above for Line COL. Thus, Lines IOL and COL were two-stage selection lines. Line IOL was derived from Line I, which had undergone eight generations of index selection. Line COL was derived from Line C, which was the randomly selected control for Line I. Line C2 was a control line derived from Line $\mathrm{C}$ and was needed because the Index and two-stage selection line litters were separated in time by 6 mo each generation. Following five generations of twostage or random selection, ovulation rate of the IOL, COL, and C2 lines averaged 18.5, 14.2, and 13.0, respectively. Pigs in all lines were managed alike, except that pigs in generation 12 of Lines I and $\mathrm{C}$ were weaned at approximately $28 \mathrm{~d}$ of age, whereas all other pigs were weaned at 10 to $13 \mathrm{~d}$ of age. All pigs were placed in a nursery from weaning to $56 \mathrm{~d}$ of age, when pigs were moved to buildings with adjustable doors over north and south wall openings to control the environment. Boars and gilts were penned separately in groups of 10. Ad libitum access to corn-soybean meal diets (Table 1) was provided.

\section{Experimental Animals and Methods}

Boars for this experiment were randomly selected (one per litter, four per paternal half-sib family) from generation 12 of Lines $I(n=61)$ and $C(n=60)$. When boars reached 90,124 , and $150 \mathrm{~d}$ of age a blood sample was taken via jugular venipuncture using vacutainer tubes containing EDTA. In generation 13, a blood sample was taken at $150 \mathrm{~d}$ from the 30 Line I boars (two from each of the 15 largest litters) and 28 Line $\mathrm{C}$ boars (two per half-sib family) that were retained as potential sires. Blood samples from gilts, one randomly selected from each litter of generation 13 in both Line I $(n=45)$ and Line $\mathrm{C}(\mathrm{n}=35)$, were collected at 58, 90, and 124 $\mathrm{d}$ of age. In generation 5 of the two-stage selection lines, blood samples were collected from gilts of Lines C2 (n $=71)$, COL $(\mathrm{n}=125)$, and IOL $(\mathrm{n}=134)$ at 58 and 124 $\mathrm{d}$ of age. Blood samples were collected at 124 and 150 $\mathrm{d}$ of age from boars retained as potential sires in Lines C2 $(n=29)$, COL $(n=29)$, and IOL $(n=30)$. Blood samples were collected from boars and gilts at different ages because maximum FSH concentrations occur during prepubertal development in gilts (Diekman et al., 1983; Camous et al., 1985) but during pubertal development in boars (Ford et al., 1997). 
Laboratory Procedures. After withdrawal, blood was immediately placed on ice for transport to the laboratory. Blood samples were centrifuged for $20 \mathrm{~min}$ at a force of $1,100 \times g$. Plasma was withdrawn, divided into two $12-\times 75-\mathrm{mm}$ polystyrene tubes, and frozen until it was analyzed by radioimmunoassay for FSH concentration. Methods for the FSH assay were described by Borg et al. (1993). The interassay coefficients of variation were 20 and $10 \%$ for reference pools that were included in each assay and had mean concentrations of 272 and $1,395 \mathrm{ng} / \mathrm{mL}$, respectively.

Statistical Methods. Traits included in the analysis were ovulation rate $(\mathrm{n}=3,058)$ and plasma concentration of FSH at 58, 90, 124, and $150 \mathrm{~d}$ of age (Table 2). Plasma concentrations of FSH at each age were treated as separate traits for two reasons. First, ovarian regulation of FSH synthesis is absent before $49 \mathrm{~d}$ of age in gilts (Colenbrander et al., 1987), and plasma concentrations of FSH in gilts gradually decline from 54 to 168 d of age (Diekman et al., 1983; Camous et al., 1985). Therefore, ovarian regulation of plasma concentration of FSH seems to become increasingly more important between 58 and $124 \mathrm{~d}$. The feedback regulatory system influencing plasma concentration of FSH is expected to have greater effect at 124 than at $58 \mathrm{~d}$. Second, data from Lines I and $\mathrm{C}$ were tested for homogeneity of variance using Bartlet's test (Snedecor and Cochran, 1989). Variance of plasma concentration of FSH was heterogeneous across lines $(P<.01)$ and ages $(P<.01)$. Transforming the data with arcsin, square root, and logarithmic transformations did not make variances homogeneous across all subclasses.

Genetic parameters were estimated with an animal model using the MTDFREML programs described by Boldman et al. (1995). All known pedigree relationships back to the sample of Large White and Landrace crossed to form the composite population were included. Traits were analyzed first with a single-trait model including direct animal genetic effect and fixed effects of sex and year. A linear covariate for actual days of age at the time of blood sampling was included in all analyses. Results of single-trait analyses were used as starting values for the two-trait analyses. Likewise, results of two-trait analyses were used as starting values for three-trait analyses. All possible two- and three-trait combinations of ovulation rate and plasma concentration of FSH at 58, 90, 124, and $150 \mathrm{~d}$ were analyzed to obtain initial estimates of covariances. An analysis including ovulation rate with plasma concentration of FSH at 58, 90, 124, and $150 \mathrm{~d}$ was attempted, but heritability of plasma concentration of FSH at $150 \mathrm{~d}$ was zero and prevented convergence. Plasma concentration of FSH at $150 \mathrm{~d}$ was dropped from the analysis, and the final analysis included only ovulation rate and plasma concentration of FSH at 58, 90, and $124 \mathrm{~d}$. Convergence criterion, variance of the likelihood values in the simplex, was set to $1.0 \times 10^{-5}$. The general form of the model was as follows:

$$
\boldsymbol{y}=\boldsymbol{X} \boldsymbol{\beta}+\boldsymbol{Z}_{\mu}+\boldsymbol{e},
$$

where $\boldsymbol{y}$ is the vector of observations for the traits in a given analysis, $\boldsymbol{\beta}, \mu$, and $\boldsymbol{e}$ are vectors of fixed, animal, and residual effects, respectively, and $\boldsymbol{X}$ and $\boldsymbol{Z}$ are known design matrices. Expectations and variances of random variables are:

$$
\boldsymbol{E}\left[\begin{array}{l}
\mu \\
\boldsymbol{e}
\end{array}\right]=\left[\begin{array}{l}
0 \\
0
\end{array}\right] ; \boldsymbol{V}\left[\begin{array}{l}
\mu \\
\boldsymbol{e}
\end{array}\right]=\left[\begin{array}{cc}
\boldsymbol{G}_{0} \otimes \boldsymbol{A} & 0 \\
0 & \boldsymbol{R}_{0} \otimes \boldsymbol{I}
\end{array}\right]
$$

where $\otimes$ denotes a direct product operation, $\boldsymbol{G}_{0}$ and $\boldsymbol{R}_{0}$ are additive genetic and residual covariance matrices, respectively, with order equal to the number of traits in the analysis, and $\boldsymbol{A}$ is the numerator relationship matrix.

After obtaining estimates of genetic parameters, estimated breeding values of each animal for all traits were calculated in MTDFREML. Line differences were tested with contrasts among estimated breeding values. Linear contrasts of $\hat{\mu}$ were generated by a vector of coefficients $(\boldsymbol{k})$. Coefficients in $\boldsymbol{k}$ were either 1 or -1 divided by the number of observations $(\boldsymbol{n})$ in each line-sex-age subclass. Plasma concentration of FSH at 58, 90, and

Table 2. Phenotypic means and standard deviations for plasma concentrations $(\mathrm{ng} / \mathrm{mL})$ of FSH at 58,90,125, and $150 \mathrm{~d}$ of age $\mathrm{a}^{\mathrm{a}}$

\begin{tabular}{lrlrccccccr}
\hline \hline Line & \multicolumn{1}{c}{$\mathrm{n}$} & Sex & \multicolumn{1}{c}{$\mathrm{d} 58$} & $\mathrm{SD}$ & $\mathrm{d} 90$ & $\mathrm{SD}$ & $\mathrm{d} 124$ & $\mathrm{SD}$ & $\mathrm{d} 150$ & SD \\
\hline I & 45 & Gilts & 1018.4 & 225.1 & 998.3 & 224.4 & 543.2 & 266.8 & & \\
C & 35 & Gilts & 812.8 & 213.3 & 782.2 & 254.1 & 440.0 & 197.0 & & \\
IOL & 134 & Gilts & 940.1 & 224.4 & & & 359.7 & 168 & & \\
COL & 125 & Gilts & 1016.5 & 305.7 & & & 422.8 & 265.7 & & \\
C2 & 71 & Gilts & 920.2 & 271.9 & & & 497.1 & 277.6 & & \\
I & 60 & Boars & & & 70.8 & 25.5 & 89.5 & 34.1 & 111.3 & 62.4 \\
C & 60 & Boars & & & 65.7 & 16.9 & 74.6 & 29.0 & 80.3 & 33.0 \\
IOL & 30 & Boars & & & & & 134.7 & 43.6 & 134 & 21.8 \\
COL & 29 & Boars & & & & & 164.4 & 74.8 & 156.1 & 49.4 \\
C2 & 29 & Boars & & & & & 169.5 & 89.7 & 174.7 & 114.6 \\
\hline
\end{tabular}

${ }^{\text {a} R a n g e s ~ i n ~ a g e s ~ w h e n ~ p l a s m a ~ c o n c e n t r a t i o n s ~ o f ~ F S H ~ w e r e ~ m e a s u r e d ~ w e r e ~} 46$ to 63,86 to 98,110 to 133 , and 147 to $153 \mathrm{~d}$. 
Table 3. Heritabilities and genetic correlations ${ }^{\mathrm{a}}$ of ovulation rate and plasma concentrations of $\mathrm{FSH}$ at 58,90 , and $124 \mathrm{~d}$ of age $\mathrm{e}^{\mathrm{b}}$

\begin{tabular}{lllll}
\hline \hline Traits & 1 & 2 & 3 & 4 \\
\hline Ovulation rate (1) & .28 & & & \\
FSH at $58 \mathrm{~d}(2)$ & .31 & .41 & & \\
FSH at $90 \mathrm{~d}(3)$ & .23 & .01 & .25 & \\
FSH at $124 \mathrm{~d}(4)$ & .00 & .32 & .89 & .12 \\
\hline
\end{tabular}

${ }^{a}$ Heritabilities are on the diagonal and genetic correlations are on the off-diagonal.

${ }^{b}$ The range in ages when plasma concentrations of FSH were measured were 46 to 63,86 to 98 , and 110 to $133 \mathrm{~d}$.

$124 \mathrm{~d}$ in gilts from Lines I and $\mathrm{C}$ were compared. Plasma concentrations of FSH at 90 and $124 \mathrm{~d}$ in boars from Lines I and $\mathrm{C}$ were compared. Plasma concentrations of FSH were contrasted at 58 and $124 \mathrm{~d}$ between Line $\mathrm{C} 2$ and Line IOL gilts and Line C2 and Line COL gilts. Plasma concentrations of FSH at $124 \mathrm{~d}$ in boars from Lines IOL and COL were each compared with those in Line C2 boars. Variance of the contrast was calculated directly in MTDFREML as $\mathrm{k}^{\prime} \mathrm{L}^{22} \mathrm{k}$, where $\mathrm{L}^{22}$ is the animal by animal part of the inverse of the coefficient matrix from the mixed model equations at convergence for the (co)variance components. Significance of differences between means was determined with a $t$-test. Denominator degrees of freedom for the $t$-test of each contrast were number of observations minus number of fixed effects minus number of covariates minus 2 .

\section{Results}

Phenotypic means and standard deviations are reported in Table 2. Selection for ovulation rate and embryonal survival did not change the pattern of decreasing FSH concentration in gilts from 58 to $124 \mathrm{~d}$ of age; however, it did cause plasma concentration of FSH in Line I to be greater than in Line C. The MTDFREML estimates of heritabilities and genetic correlations are given in Table 3 . Heritability of ovulation rate was estimated to be .28. This is consistent with previous estimates from this population (Johnson et al., 1999). Heritabilities of plasma concentration of FSH at 58, 90, 124, and $150 \mathrm{~d}$ were estimated to be $.41, .25, .12$, and 0 , respectively. Estimates of genetic correlations between plasma concentration of FSH at 58, 90, and $124 \mathrm{~d}$ with ovulation rate were $.31, .23$, and 0 , respectively. Genetic correlations between plasma concentrations of FSH at various ages ranged from .01 to .89 .

Contrasts of estimated breeding values are given in Table 4. Heritability of plasma concentration of FSH at $150 \mathrm{~d}$ was estimated to be 0 . No contrasts for that trait were made. Gilts from Line I had greater EBV for plasma concentration of FSH at $58 \mathrm{~d}$ and $90 \mathrm{~d}$ than those from Line $\mathrm{C}(P<.01)$. Line COL gilts had greater EBV for plasma concentration of FSH at $58 \mathrm{~d}$ than line $\mathrm{C} 2$ gilts $(P<.01)$. Estimated breeding values of plasma concentration of FSH at $90 \mathrm{~d}$ in Line I boars were greater than those for Line $\mathrm{C}$ boars $(P<.05)$.

\section{Discussion}

Ovarian regulation of FSH synthesis is absent prior to $49 \mathrm{~d}$ of age in gilts (Colenbrander et al., 1987). In the present study, differences between lines occurred at $58 \mathrm{~d}$. Therefore, the biological mechanism by which selection altered plasma concentration of FSH most likely is due to increased FSH synthesis and not to a change in ovarian feedback regulation. Lines did not differ at $150 \mathrm{~d}$ of age, which suggests that negative feedback mechanisms had matured to the point at which potential for synthesis was not the rate-limiting step in FSH secretion. Thus, the heritability of FSH at $150 \mathrm{~d}$ of age was estimated to be zero. The decline in plasma concentration of FSH from 58 to $124 \mathrm{~d}$ of age in gilts (Table 2) is similar to results of Diekman et al. (1983), who reported a decline in concentration of FSH from 70 to $126 \mathrm{~d}$ of age, and Camous et al. (1985), who reported a decline in concentration of FSH from 54 to $168 \mathrm{~d}$ of age.

Ovulation rates significantly greater than those of domestic breeds have been reported in Meishan gilts (Christenson, 1993; White et al., 1993) and mature Meishan females (Anderson et al., 1993; Christenson, 1993). Greater plasma concentration of FSH was observed in mature boars from the Meishan breed than in those of the Duroc breed (Borg et al., 1993) or a whiteline composite population ( $1 / 4$ Chester White, Yorkshire, Landrace, and Large White breeds; Howard et al., 1993). Differences in plasma concentration of FSH between breeds differing in ovulation rate support the hypothesis that FSH and ovulation rate are genetically correlated.

Results of the present study differ from those of a previous comparison of pigs of lines I and C. Mariscal et al. (1996) sampled pigs from these lines at between $1 \mathrm{wk}$ and 6 mo of age. No significant differences between lines in plasma concentration of FSH were found. Mariscal et al. (1996) used the index of ovulation rate and embryonal survival to select six sons of the five highest-indexing and six sons of the five lowest-indexing females in both Lines I and C. In the present study, 60 boars were randomly selected from both Lines $\mathrm{I}$ and C. Thus, differences in sampling criteria and(or) sample size may explain the fact that differences between lines for concentration of FSH at $90 \mathrm{~d}$ were found in the present study but not in the previous study.

Using a crossbred Meishan population, Rohrer et al. (1997) estimated heritability of plasma concentration of FSH to be .42 in males 120 to $180 \mathrm{~d}$ of age and the genetic correlation with ovulation rate in females to be -.06. Unlike the study by Rohrer et al. (1997), concentration of FSH was measured in both males and females in the present study. At $124 \mathrm{~d}$, the estimated heritability was .12 and the genetic correlation between concentration of FSH and ovulation rate was 0 . The estimated 
Table 4. Contrasts between lines of mean estimated breeding values for plasma concentrations of FSH

\begin{tabular}{llllll}
\hline \hline Age, $\mathrm{d}^{\mathrm{a}}$ & \multicolumn{1}{c}{ Contrast } & Sex & Contrast & \multicolumn{1}{c}{ SE } & $t$-Test \\
\hline 58 & Line I-Line C & Gilts & 1.89 & $3.62 \times 10^{-1}$ & $5.22^{* * *}$ \\
58 & Line IOL-Line C2 & Gilts & $4.91 \times 10^{-1}$ & $2.98 \times 10^{-1}$ & 1.65 \\
58 & Line COL-Line C2 & Gilts & $8.76 \times 10^{-1}$ & $2.99 \times 10^{-1}$ & $2.93^{* *}$ \\
90 & Line I-Line C & Boars & $2.78 \times 10^{-1}$ & $1.28 \times 10^{-1}$ & $2.17^{*}$ \\
90 & Line I-Line C & Gilts & $5.65 \times 10^{-1}$ & $1.37 \times 10^{-1}$ & $4.12^{* *}$ \\
124 & Line I-Line C & Boars & $-2.0 \times 10^{-2}$ & $8.74 \times 10^{-2}$ & -.22 \\
124 & Line IOL-Line C2 & Boars & $-3.68 \times 10^{-2}$ & $9.14 \times 10^{-2}$ & -.40 \\
124 & Line COL-Line C2 & Boars & $3.39 \times 10^{-2}$ & $9.59 \times 10^{-2}$ & .35 \\
124 & Line I-Line C & Gilts & $1.63 \times 10^{-1}$ & $9.96 \times 10^{-2}$ & 1.64 \\
124 & Line IOL-Line C2 & Gilts & $-8.44 \times 10^{-2}$ & $6.76 \times 10^{-2}$ & -1.25 \\
124 & Line COL-Line C2 & Gilts & $-7.38 \times 10^{-3}$ & $7.23 \times 10^{-2}$ & -.10 \\
\hline
\end{tabular}

aThe range in ages when plasma concentrations of FSH were measured were 46 to 63,86 to 98,110 to 133 , and 147 to $153 \mathrm{~d}$.

$* P<.05$.

$* * P<.01$.

genetic correlations from the two studies are in good agreement with each other. Differences in sampling age, population structure, crossbred vs selection lines, or the fact that Rohrer et al. (1997) measured concentration of FSH only in males may explain the differences in the heritability estimates.

Conclusions from the present study are that selection for increased index values of ovulation rate and embryonic survival resulted in greater plasma concentration of FSH in boars at $90 \mathrm{~d}$ and in gilts at 58 and $90 \mathrm{~d}$. Plasma concentrations of FSH were not measured in boars at $58 \mathrm{~d}$ of age. The present study, along with those of Borg et al. (1993) and Howard et al. (1993), provides evidence of a positive genetic correlation between ovulation rate and plasma concentration of FSH. In populations of the same size, greater selection intensity can be realized by selecting for plasma concentration of FSH than by selecting for ovulation rate, because FSH can be measured in both males and females. At $58 \mathrm{~d}$, plasma concentration of FSH was moderately heritable in gilts and positively correlated with ovulation rate and sufficient phenotypic variance existed for selection to be effective. The ratio of correlated response in ovulation rate when selecting for increased plasma concentration of FSH to response to direct selection for increased ovulation rate was estimated to be:

$$
\begin{aligned}
{\left[\frac{\left(\mathrm{i}_{\mathrm{m}}+\mathrm{i}_{\mathrm{f}}\right) \times \mathrm{h}_{\mathrm{fsh}} \times \mathrm{r}_{\mathrm{fsh}, \mathrm{or}}}{\mathrm{i}_{\mathrm{f}} \times \mathrm{h}_{\mathrm{or}}}\right] } & =\left[\frac{((2.063+1.4) \times .64 \times .31)}{(1.4 \times .53)}\right] \\
& =.93
\end{aligned}
$$

assuming the same genetic correlation in males and females between plasma concentration of FSH and ovulation rate and the same heritability at $58 \mathrm{~d}$ of age. Selection for increased plasma concentration of FSH is expected to increase ovulation rate in pigs. However, there are possible negative consequences of such selection. Increased plasma concentration of FSH has been associated with decreased testicular weight and total daily sperm production in boars (Lunstra et al., 1996; Ford et al., 1997; Zanella et al., 1999). It may be necessary to combine selection for increased plasma concentration of FSH in males with selection for increased testis size.

\section{Implications}

Plasma concentration of follicle-stimulating hormone (FSH) at $58 \mathrm{~d}$ of age in gilts and at $90 \mathrm{~d}$ of age in boars and gilts was moderately heritable and correlated with ovulation rate. The ideal age for measuring plasma concentration of FSH is not known. However, selection for increased plasma concentration of FSH was estimated to be $93 \%$ as effective in changing ovulation rate as direct selection for ovulation rate and thus may be a practical method for increasing ovulation rate without using laparoscopy.

\section{Literature Cited}

Anderson, R. H., L. K. Christenson, R. K. Christenson, and S. P. Ford. 1993. Investigations into the control of litter size in swine: II Comparisons of morphological and functional embryonic diversity between Chinese and American breeds. J. Anim. Sci. 71:1566-1571.

Bennett, G. L., and K. A. Leymaster. 1989. Integration of ovulation rate, potential embryonic viability and uterine capacity into a model of litter size in swine. J. Anim. Sci. 67:1230-1241.

Boldman, K. G., L. A. Kriese, L. D. Van Vleck, C. P. Van Tassell, and S. D. Kachman. 1995. A manual for use of MTDFREML. A set of programs to obtain estimates of variances and covariances [Draft]. ARS, USDA, Washington, DC.

Borg, K. D., D. D. Lunstra, and R. K. Christenson. 1993. Semen characteristics, testicular size, and reproductive hormone concentrations in mature Duroc, Meishan, Fengjing, and Minzhu boars. Biol. Reprod. 49:515-521.

Camous, S., A. Prunier, and J. Pelletier. 1985. Plasma prolactin, LH, FSH, and estrogen excretion patterns in gilts during sexual development. J. Anim. Sci. 60:1308-1317.

Christenson, R. K. 1993. Ovulation rate and embryonic survival in Chinese Meishan and white crossbred pigs. J. Anim. Sci. 1:3060-3066. 
Colenbrander, B., J. C. Meyer, A. A. MacDonald, D. F. M. Van De Wiel, B. Engel, and F. H. De Jong. 1987. Feedback regulation of gonadotropic hormone secretion in neonatal pigs. Biol. Reprod. 36:871-877.

Diekman, M. A., W. E. Trout, and L. L. Anderson. 1983. Serum profiles of LH, FSH, and prolactin from 10 weeks of age until puberty in gilts. J. Anim. Sci. 56:139-145.

Ford, J. J., T. H. Wise, and D. D. Lunstra. 1997. Negative relationships between blood concentrations of follicle-stimulating hormone and testicular size in mature boars. J. Anim. Sci. 75:790-795.

Howard, H. J., J. Klindt, A. J. Conley, T. H. Wise, and J. J. Ford. 1993. Fourth International Conference on Pig Reproduction, Univ. of Missouri-Columbia. p 117 (Abstr.).

Johnson, R. K., M. K. Nielsen, and D. S. Casey. 1999. Responses in ovulation rate, embryonal survival, and litter traits in swine to 14 generations of selection to increase litter size. J. Anim. Sci. 77:541-557.

Johnson, R. K., D. R. Zimmerman, and R. J. Kittok. 1984. Selection for components of reproduction in swine. Livest. Prod. Sci. 11:541-558.

Lunstra, D. D., J. J. Ford, and T. H. Wise. 1996. Selection for extremes in serum FSH concentrations results in reduced testis size and fertility in Meishan and White Composite boars. In: Tumbleson and Schook (Ed.) Advances in Swine in Biomedical Research. pp 523-531. Plenum Press, New York.
Mariscal, D. V., P. L. Wolfe, E. G. Bergfeld, A. S. Cupp, F. N. Kojima, K. E. Fike, T. Sanchez, M. E. Wehrman, R. K. Johnson, R. J. Kittok, J. J. Ford, and J. E. Kinder. 1996. Comparison of circulating concentrations of reproductive hormones in boars of lines selected for size of testes or number of ovulations and embryonal survival to concentrations in respective control lines. J. Anim. Sci. 74:1905-1914.

Neal, S. M., R. K. Johnson, and R. J. Kittok. 1989. Index selection for components of litter size in swine: Response to five generations of selection. J. Anim. Sci. 67:1933-1945.

Rohrer, G. A., J. J. Ford, T. H. Wise, and L. D. Young. 1997. Estimates of genetic correlations between serum FSH concentrations in males and measures of female reproduction in a crossbred Meishan population of pigs. J. Anim. Sci. 75(Suppl. 1):31 (Abstr.).

Smith, C., G. E. Dickerson, M. W. Tess, and G. L. Bennett. 1983. Expected relative response to selection for alternative measures of life cycle economic efficiency of pork production. J. Anim. Sci. 56:1306-1314.

Snedecor, G. W., and W. G. Cochran. 1989. Statistical Methods (8th Ed.). p 251. Iowa State University Press, Ames.

White, B. R., D. G. McLaren, P. J. Dziuk, and M. B. Wheeler. 1993. Age at puberty, ovulation rate, uterine length, prenatal survival and litter size in Chinese Meishan and Yorkshire females. Theriogenology 40:85-97.

Zanella, E., D. Lunstra, T. Wise, J. Kinder, and J. Ford. 1999. Testicular morphology and function in boars differing in concentrations of plasma follicle-stimulating hormone. Biol. Reprod. 60:115118. 